\section{Nucleobase participation in ribozyme catalysis}

Zheng-yun Zhao, Aileen McLeod, Shinya Harusawa, Lisa Araki, Maho Yamaguchi, Takushi Kurihara and David M.J. Lilley

\section{Supplementary information}

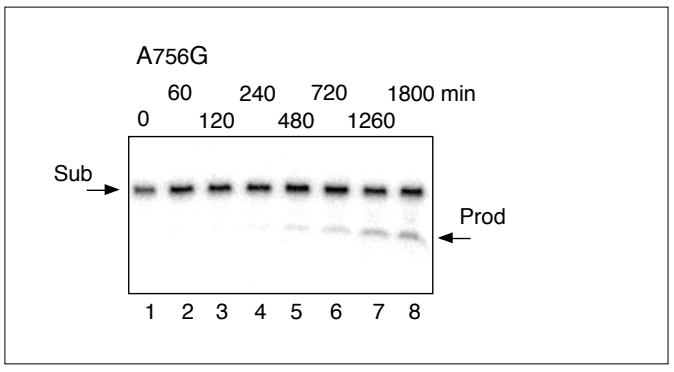

Figure S1 Time course of a cleavage reaction using $1 \mu \mathrm{M}$ A756G ribozyme under single-turnover conditions identical to those used in Figure 2. Tracks 1-8 are the results of incubation for $0,60,120,240,480,720,1260$ and $1800 \mathrm{~min}$ respectively. In contrast to the experiments in Figure 2A-C, electrophoresis was performed using $5 \mathrm{~cm}$ plates, and thus the different product species are not resolved under these conditions. Note that very little cleavage occurs even after the longest time of incubation.

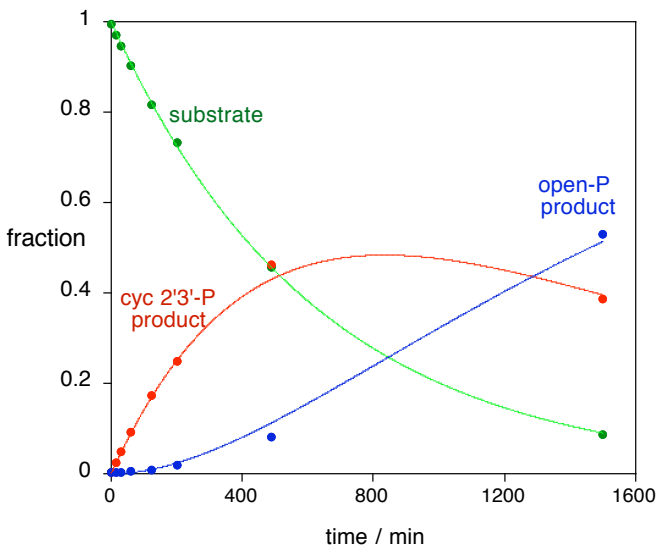

Figure S2 The cleavage of the substrate (S) and formation of the cyclic $(\mathbf{C})$ and open $(\mathbf{O})$ products by the A756Imz ribozyme fit a sequential conversion process, ie $\mathbf{S}->\mathbf{C}->\mathbf{O}$. The fraction of each species has been quantified and plotted as a function of incubation time ( $t$ ), and fitted to the integrated rate equations that are appropriate for the sequential model, ie

$$
\begin{aligned}
& \operatorname{frac}(\mathrm{S})=\mathrm{e}^{-\mathrm{k}_{1} \mathrm{t}} ; \operatorname{frac}(\mathrm{C})=\frac{\mathrm{k}_{1}}{\mathrm{k}_{2}-\mathrm{k}_{1}}\left(\mathrm{e}^{-\mathrm{k}_{1} \mathrm{t}}-\mathrm{e}^{-\mathrm{k}_{2} \mathrm{t}}\right) \\
& \operatorname{frac}(\mathrm{O})=1+\frac{1}{\mathrm{k}_{1}-\mathrm{k}_{2}}\left(\mathrm{k}_{2} \mathrm{e}^{-\mathrm{k}_{1} \mathrm{t}}-\mathrm{k}_{1} \mathrm{e}^{-\mathrm{k}_{2} \mathrm{t}}\right)
\end{aligned}
$$

where the rate of ribozyme cleavage is $k_{1}$ and the rate of cyclic phosphate hydrolysis is $\mathrm{k}_{2}$.

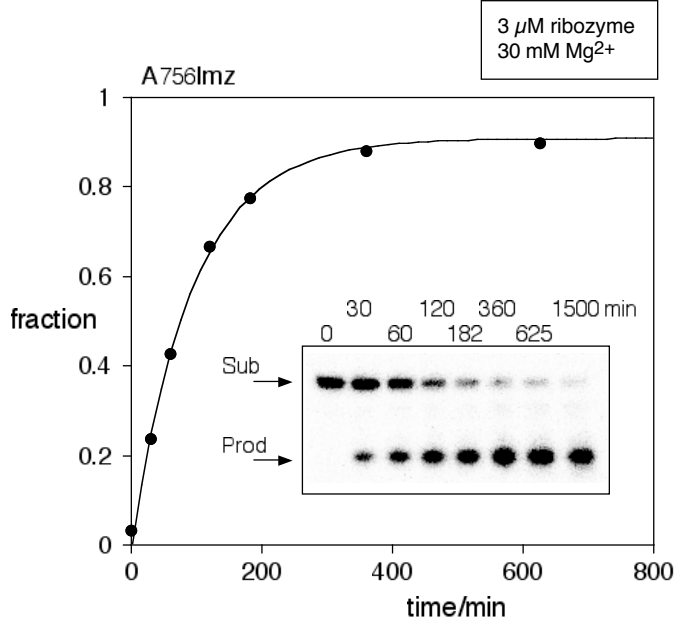

Figure S3 The rate of the cleavage reaction by the imidazole-containing VS ribozyme under optimized conditions. A cleavage reaction in elevated $\mathrm{Mg}^{2+}$ ion and ribozyme concentration. Time course of a cleavage reaction using $3 \mu \mathrm{M}$ A756Imz ribozyme under single-turnover conditions, in the presence of $50 \mathrm{mM}$ Tris. $\mathrm{HCl}(\mathrm{pH} 8.0)$, $30 \mathrm{mM} \mathrm{MgCl}_{2}, 2 \mathrm{mM}$ spermidine, $25 \mathrm{mM} \mathrm{KCl}$ at $37^{\circ} \mathrm{C}$. The extent of cleavage as a function of time are well fitted by a single exponential function, with a rate of $0.01 \mathrm{~min}^{-1}$. Tracks $1-8$ are the results of reactions of $0,30,60,120,182,360$, 625 and $1500 \mathrm{~min}$ respectively.

\section{MATERIALS AND METHODS}

Chemical synthesis of RNA

C4-linked imidazole ribonucleoside phosphoramidite with a pivaloyloxymethyl group was synthesised as described previously $^{1}$. The lower strand of the modified VS ribozyme was synthesised on a 200 nmole dT support using phosphoramidite chemistry ${ }^{2}$ implemented on an Applied Biosystems 394 DNA/RNA synthesizer. Ribonucleoside $\beta$ cyanoethyl phosphoramidites were obtained from PrOligo as rA [4-( $t$-butylphenoxy)-acetyl] (tac), $\mathrm{rG}(\operatorname{tac}), \mathrm{rC}(\operatorname{tac})$ and $\mathrm{U}$ with 2'- $t$-BDMS protection. DCI (PrOligo) was used as an activator. The capping A reagent was replaced by $\left(\operatorname{tac}_{2} \mathrm{O}\right)$ (PrOligo). $17 \mathrm{mg}$ of the imidazole phosphoramidite were dissolved in $20 \mu \mathrm{l}$ anhydrous acetonitrile and coupled for 15 min. An average coupling yield of $99 \%$ was observed based on the trityl cation released when imidazole was added into sequence. Oligoribonucleotides were deprotected in $25 \%$ ethanol/ammonia solution at $55^{\circ} \mathrm{C}$ for $4 \mathrm{~h}$., and evaporated to dryness. They were dissolved in $0.5 \mathrm{ml} 1 \mathrm{M}$

tetrabutylammonium fluoride (Aldrich) in tetrahydrofuran to remove $t$-BDMS groups, and agitated at $20^{\circ} \mathrm{C}$ in the dark for $16 \mathrm{~h}$. prior to desalting by G25 Sephadex (Pharmacia) and ethanol precipitation. Fully deprotected oligonucleotides were purified by electrophoresis in $20 \%$ polyacrylamide gels containing $7 \mathrm{M}$ urea. Bands were excised, and oligonucleotides electroeluted into $8 \mathrm{M}$ ammonium acetate and recovered by ethanol precipitation.

\section{Synthesis of RNA by in vitro transcription}

The upper ribozyme strand was generated by in vitro transcription from a template made by recursive PCR from chemically synthesised deoxyribooligonuceotides. RNA was transcribed using T7 RNA polymerase ${ }^{3}$ from double-stranded DNA templates. Templates for transcription of ribozymes were made by recursive PCR from synthetic DNA oligonucleotides. RNA was purified by electrophoresis in $8 \%$ 
or $20 \%$ polyacrylamide gels containing $7 \mathrm{M}$ urea. RNA was recovered from crushed gel slices by elution in water at $4{ }^{\circ} \mathrm{C}$ overnight. Eluted RNA was filtered, recovered by ethanol precipitation and dissolved in water. Ligation substrates were made by in vitro transcription from single stranded templates annealed to a short promoter sequence. Ligation substrates treated with VS ribozyme to produce the mature sequences, as described previously ${ }^{4}$.

\section{RNA sequences}

The sequences used in these studies were (all written 5' to

$\left.3^{\prime}\right)$ :

Upper ribozyme strand :

GGAAGCAGGGAACUCACCUCCAAUUUCAGUACUGA

AAUUGUCGUAGCAGUUGACUACUGUUAUGUGAUU GGUAGAGGCUAAGUGACGGUAGUGGA

Lower ribozyme strand :

UCCACUAUUGCAGCACAGCACAAGCCCGCUUCCdT

A756 is shown in underscored, and was replaced by guanine or imidazole as required.

Cleavage reaction substrate :

GCGCGAAGGGCGUCGUCGCCCCGA

Ligation reaction substrate : GCGGUGUCGCAAUCUGCG

(terminated by cyclic 2'3'-phosphate) and

HOAAGGGCGUCGUCGCCCCGAGCGGAUUGCGACAC

\section{Cleavage reactions}

Ribozyme cleavage reactions were performed under single turnover conditions using a trace concentration of radioactively $\left[5{ }^{-}-{ }^{32} \mathrm{P}\right]$-labeled substrate and an excess of twopiece ribozyme. Equal volumes of substrate and a mixture of each ribozyme strand were incubated separately in the presence of $20 \mathrm{mM}$ Tris. $\mathrm{HCl}$ ( $\mathrm{pH} 8.0$ ), $10 \mathrm{mM} \mathrm{MgCl}_{2}$ (or as indicated), $2 \mathrm{mM}$ spermidine and $25 \mathrm{mM} \mathrm{KCl}$ at $37^{\circ} \mathrm{C}$ for 30 min before mixing together to initiate the ribozyme reaction (final volume $20 \mu \mathrm{l}$ containing $\sim 1 \mathrm{nM}$ substrate and $1 \mu \mathrm{M}$ of each ribozyme strand). $2 \mu$ Aliquots were removed at selected times and the reaction terminated by addition of $8 \mu \mathrm{l}$ of $95 \%$ formamide, $20 \mathrm{mM}$ EDTA, $0.05 \%(\mathrm{w} / \mathrm{v})$ xylene cyanol FF and $0.05 \%(\mathrm{w} / \mathrm{v})$ bromophenol blue (termination mixture). The products were analysed by polyacrylamide gel electrophoresis under denaturing conditions, and quantified by phosphorimaging.

\section{Ligation reactions}

Substrate and ribozyme were annealed in separate tubes in the presence of $50 \mathrm{mM}$ Tris. $\mathrm{HCl}(\mathrm{pH} 8.0), 10 \mathrm{mM} \mathrm{MgCl}, 2 \mathrm{mM}$ spermidine and $25 \mathrm{mM} \mathrm{KCl}$ at $25^{\circ} \mathrm{C}$. The substrate comprised radioactively $\left[5,{ }^{32} \mathrm{P}\right]$-labelled 5 ' strand terminated by a ''3'cyclic phosphate in trace concentration $(<1 \mathrm{nM})$ plus an excess $(100 \mathrm{nM})$ of unlabelled 3' strand terminated with 5'OH. The ribozyme comprised $1 \mu \mathrm{M}$ each of unlabelled upper and lower strands. The reaction was initiated by mixing ribozyme and substrate.

\section{Acid hydrolysis reactions}

$4 \mu \mathrm{l}$ Aliquots taken from natural or A756Imz VS ribozyme reactions were mixed with equal volume of $0.2 \mathrm{M} \mathrm{HCl}$ solution, and hydrolysis allowed to proceed at $37^{\circ} \mathrm{C}$ for $4 \mathrm{~h} .4$ $\mu \mathrm{l}$ Aliquots were then removed and terminated by addition of $6 u l$ of termination mixture.

\section{Gel electrophoretic analysis of ribozyme} products

Substrate and product were separated by electrophoresis in $20 \%$ polyacrylamide gels containing $7 \mathrm{M}$ urea. In order to separate the cyclic and open phosphate products, $45 \mathrm{~cm}$ sequencing gels were used. In other analyses, $5 \mathrm{~cm}$ gels were employed. Radioactivity was quantified by exposure to a storage phosphor screens and imaging (Fuji BAS-1500). Data were fitted to single exponential functions by regression analysis using the initial part of the progress curve (Kalaidagraph, Abelbeck Software)
1. Araki, L., Harusawa, S., Yamaguchi, M., Yonezawa, S. Taniguchi, N., Lilley, D. M. J., Zhao, Z., and Kurihara, T. (2004) Tetrahedron Lett. 45, 2657-2661

2. Beaucage, S. L., and Caruthers, M. H. (1981) Tetrahedron Letters 22, 1859-1862.

3. Milligan, J. F., Groebe, D. R., Witherall, G. W., and Uhlenbeck, O. C. (1987) Nucleic Acids Res. 15, 8783-8798. 4. McLeod, A. C., and Lilley, D. M. J. (2004) Biochemistry $43,1118-1125$. 